\title{
Using Cheap-Talk as a Test of Validity in Choice Experiments
}

\author{
Fredrik Carlsson ${ }^{\mathrm{A}}$ \\ Peter Frykblom ${ }^{\mathrm{B}}$ \\ Carl-Johan Lagerkvist ${ }^{\mathrm{C}}$
}

\author{
Working Papers in Economics no. 128 \\ March 2004 \\ Department of Economics \\ Gothenburg University
}

\begin{abstract}
In two experiments on the choice of consumer goods, the estimated marginal willingness to pay for food are found to be lower in the survey version with cheap talk. Our test can be seen as a test of hypothetical bias. This implies we cannot reject the hypothesis of a hypothetical bias for marginal WTP in choice experiments.
\end{abstract}

JEL classification: C91, Q13

Key words: hypothetical WTP, cheap talk, incentive compatibility.

The authors acknowledge financial support from the project MAT21, Swedish University of Agricultural Sciences. The authors thank Jason Lusk, Tim Perri and Olof Johansson-Stenman for advice and comments.

A Department of Economics, Göteborg University, Box 640, 40530 Göteborg, Sweden; Ph +46 31 7734174; E-mail fredrik.carlsson@economics.gu.se.

B (corresponding author): Department of Economics, Appalachian State University, Boone, North Carolina 28608-2051, phone: 828.262.6121, fax: 828.262.6105, e-mail: frykblomlp@appstate.edu

${ }^{\mathrm{C}}$ Department of Economics, Swedish University of Agricultural Sciences; Ph +46 18 671783; E-mail: Carl-Johan.Lagerkvist@ekon.slu.se 


\section{Introduction}

The value of a good is often of interest to the applied economist. Often this value is readily available in existing markets; other times it is necessary to create an experiment where the respondent is asked to make hypothetical or real trade-offs between price and product quality. Environmental and agricultural economics are two fields where hypothetical experiments have been used extensively. In environmental economics, the focus has often been on public good attributes, while in agricultural economics the focus has been on attributes of private goods that still do not exist in the market. While so-called contingent valuation (CV) experiments previously were the main applied methodology, lately there has been an interest in choice experiments (CE). Both survey methods ask the respondent to make hypothetical trade-offs, a feature that enables us to test for currently non-existent, as well as public, attributes.

Stated preference experiments are controversial. During the 1990s, there was an intensive debate about the possibility of using $\mathrm{CV}$ as a survey method of preferences. The method came under heavy criticism; many scientific articles on the implementation and usefulness of results were published. Much of this debate concerned the question of the validity of the results, in particular the hypothetical nature of the experiments. Several attempts were made to reduce the influence of this hypothetical bias. Cheap talk scripts seemed to be one of the most successful attempts. Initially suggested by Cummings and Taylor (1999), cheap talk is an attempt to bring down the hypothetical bias by thoroughly describing and discussing the propensity of respondents to exaggerate stated willingness to pay (WTP). Using private goods, classroom experiments, or closely controlled field settings, the use of cheap-talk proved to be potentially successful, (see Cummings and Taylor, 1999 and List, 2001). While the hypothetical mean WTP without cheap-talk was 
significantly higher than WTP using actual economic commitments, the hypothetical WTP with cheap-talk script could not be shown to be statistically significantly different from the actual WTP.

There are surprisingly few published studies that test for hypothetical bias in CE. Both Carlsson and Martinsson (2002) and Cameron et al. (2002) fail to reject a hypothesis of equal marginal WTP in both a real and a hypothetical setting, while Johansson-Stenman and Svedsäter (2003) rejects the equality of marginal WTPs and Lusk and Schroeder (2003) find that hypothetical total WTP for the good exceeds real WTP, but fails to reject the equality of marginal WTPs for changes in the single attributes. Another way to test the validity of $\mathrm{CE}$ is to test the impact of a cheap-talk script. In this paper we report the results of such a test. In section 2, we describe the choice experiment, the test, and the econometric model. In section 3, we report the results, and Section 4 we conclude.

\section{The Choice Experiment}

Each respondent received a questionnaire containing a choice experiment concerning the purchase of two consumer goods: chicken and ground beef. Half of the individuals received a questionnaire with a cheap talk script; the remaining questionnaires did not include any such script. The questionnaire consists of three parts. The first part includes questions about the household's habits regarding food consumption. The choice experiment constitutes the second part, and questions regarding the respondent's socio-economic status is the third part.

In the introduction to the choice experiment, the purpose of the survey is briefly explained. This is followed by a description of the different attributes of the goods. The 
respondents were also provided with a separate fact sheet providing a description of each attribute. The cheap talk treatment contained the following text:

The experience from previous similar surveys is that people often respond in one way but act differently. It is particular common that one states a higher willingness to pay than what one actually is willing to pay for the good in the store. We believe this is due to the fact that one does not really consider how big an impact an extra cost actually has to the family budget. It is easy to be generous when one does not really need to make the choices in a store. If you have another idea or comment on what this behavior depends on, please write this down on the last page of the questionnaire.

For each product, respondents answered four choice sets, i.e. eight choice sets in total. An example of a choice situation is presented in the Appendix. The choice sets were created using a cyclical design principle (Bunch, Louviere, and Andersson 1996).

Assuming a linear indirect utility function, the utility of alternative $i$ in choice situation $t$ for individual $k$ is

$$
V_{i t k}=\beta^{\prime} a_{i t}+\lambda\left(y_{k}-\operatorname{cost}_{i t}\right)+\varepsilon_{i t k}
$$

where $a_{i}$ is the attribute vector, $\beta$ is the corresponding parameter vector, $y_{k}$ is income, and $\varepsilon_{i t k}$ is an error term. From this specification the mean marginal willingness to pay for a certain attribute is the ratio of the attribute coefficient and the price coefficient, $\lambda$, (Hanemann, 1984). ${ }^{1}$ The probability that individual $k$ will chose alternative $i$ can be expressed as

$$
P_{i t k}=P\left\{\beta^{\prime} a_{i t}+\lambda\left(y_{k}-\operatorname{cost}_{i t}\right)+\varepsilon_{i t k}>\beta^{\prime} a_{j t}+\lambda\left(y_{k}-\operatorname{cost}_{j t}\right)+\varepsilon_{j t k}>; \forall j \neq i\right\}
$$

In the analysis of the responses, a random parameter logit model is applied. In such a model, unobserved taste variation among individuals is explicitly treated (e.g. Train,

\footnotetext{
${ }^{1}$ When the model is estimated, the income variable drops out since only differences in utility affect the choice probabilities.
} 
2003). We assume that the cost coefficient is normally distributed, while all other attribute coefficients are fixed. The data has a panel structure since we observe the respondents over a sequence of choices. In the analysis we pool the two choice experiments for the two goods and assume that the randomly distributed cost coefficient is constant across the choice situations for each individual. This reflects an underlying assumption of stable preference structures for all individuals.

\section{Results}

The population that the sample was drawn from was defined as those between 18 and 75 years with a permanent address in Sweden. A random sample of 1600 individuals was selected from the Swedish census registry. A mail survey was conducted in the fall of 2003; two reminders were sent out within a two-week interval to those that had not replied. In total 827 (52\%) individuals returned the questionnaire, of which 794 were available for analysis due to non-responses to various questions. Table 1 presents the result for the random parameter logit model. The model is estimated with simulated maximum likelihood using Halton draws with 250 replications. $^{2}$

\footnotetext{
${ }^{2}$ See Train (2003) for details on simulated maximum likelihood and Halton draws.
} 
Table 1. Results random parameter logit model.

\begin{tabular}{|c|c|c|c|c|c|}
\hline & \multicolumn{2}{|c|}{ With cheap talk } & \multicolumn{2}{|c|}{ Without cheap talk } \\
\hline & & Coeff & $P$-value & Coeff & P-value \\
\hline \multicolumn{6}{|c|}{ Random parameters } \\
\hline $\mathrm{Cos}$ & & -0.0594 & 0.000 & -0.0318 & 0.000 \\
\hline \multicolumn{6}{|c|}{ Standard deviation } \\
\hline $\mathrm{Cos}$ & & 0.0870 & 0.000 & 0.0886 & 0.000 \\
\hline \multicolumn{6}{|c|}{ Fixed parameters } \\
\hline \multirow{5}{*}{ 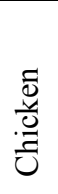 } & Growth & 0.7491 & 0.000 & 0.6484 & 0.000 \\
\hline & GMO: Ban & 0.8076 & 0.000 & 0.8434 & 0.000 \\
\hline & GMO: Market & 0.2454 & 0.015 & 0.4044 & 0.000 \\
\hline & Out summer & 0.1643 & 0.042 & 0.2855 & 0.000 \\
\hline & Mobile & -0.2876 & 0.000 & -0.1408 & 0.036 \\
\hline \multirow{5}{*}{$\stackrel{d}{\infty}$} & Improved labelling & 0.3651 & 0.000 & 0.1464 & 0.027 \\
\hline & GMO: Ban & 0.8952 & 0.000 & 1.1678 & 0.000 \\
\hline & GMO: Market & 0.3040 & 0.000 & 0.5482 & 0.000 \\
\hline & Out all year & 0.1228 & 0.073 & 0.0391 & 0.570 \\
\hline & Mobile & 0.2278 & 0.000 & 0.1936 & 0.002 \\
\hline \multicolumn{2}{|c|}{ Log-likelihood } & \multicolumn{4}{|r|}{3526.387} \\
\hline \multicolumn{2}{|c|}{ Nobs } & \multicolumn{4}{|c|}{794 individuals/5922 choice situations } \\
\hline
\end{tabular}

Using a likelihood ratio test, we reject the hypothesis of equal parameters between the two experiments with and without cheap talk at the $99 \%$ level. However, the pooling of two different data sets is problematic since the estimated parameters are confounded with the respective scale parameters. One way of dealing with this problem is to first test for a difference in scale between the data sets. We do this using the grid search procedure proposed by Swait and Louviere (1993). ${ }^{3}$ Using a likelihood ratio test we cannot reject the hypothesis of equal scale parameters either ( $p$-value $=0.60)$. There is thus a significant difference in preferences between the survey version with and without cheap talk. Table 2 reports the marginal WTPs for each attribute.

\footnotetext{
${ }^{3}$ When estimating the random parameter models with the grid search procedure, 50 replications were used instead of 250 .
} 
Table 2. Estimated mean marginal WTP in SEK $/ \mathrm{kg}$. 95\% confidence intervals estimated with the Krinsky-Robb (1986) method using 1000 replications.

\begin{tabular}{|c|c|c|c|}
\hline & & Cheap talk & No cheap talk \\
\hline \multirow{5}{*}{ 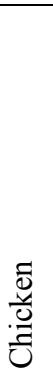 } & Growth & $\begin{array}{c}12.60 \\
(8.89,16.33) \\
\end{array}$ & $\begin{array}{c}20.38 \\
(10.99,29.77)\end{array}$ \\
\hline & GMO: Ban & $\begin{array}{c}13.59 \\
(9.37,17.80)\end{array}$ & $\begin{array}{c}26.51 \\
(14.81,38.22)\end{array}$ \\
\hline & GMO: Market & $\begin{array}{c}4.13 \\
(0.76,7.50)\end{array}$ & $\begin{array}{c}12.71 \\
(5.39,20.03)\end{array}$ \\
\hline & Out summer & $\begin{array}{c}2.76 \\
(0.02,5.50) \\
\end{array}$ & $\begin{array}{c}8.97 \\
(3.11,14.84) \\
\end{array}$ \\
\hline & Mobile & $\begin{array}{c}-4.84 \\
(-7.26,-2.39) \\
\end{array}$ & $\begin{array}{c}-4.42 \\
(-8.91,0.6) \\
\end{array}$ \\
\hline \multirow[b]{5}{*}{ 离 } & Improved labeling & $\begin{array}{c}6.14 \\
(3.56,8.71)\end{array}$ & $\begin{array}{c}4.60 \\
(0.09,9.11)\end{array}$ \\
\hline & GMO: Ban & $\begin{array}{c}15.06 \\
(10.92,19.21)\end{array}$ & $\begin{array}{c}36.71 \\
(22.52,50.89)\end{array}$ \\
\hline & GMO: Market & $\begin{array}{c}5.11 \\
(2.26,7.97)\end{array}$ & $\begin{array}{c}17.23 \\
(9.40,25.07)\end{array}$ \\
\hline & Out all year & $\begin{array}{c}2.07 \\
(-0.24,4.38)\end{array}$ & $\begin{array}{c}1.23 \\
(-3.05,5.50)\end{array}$ \\
\hline & Mobile & $\begin{array}{c}3.83 \\
(1.58,6.08)\end{array}$ & $\begin{array}{c}6.09 \\
(1.58,10.59)\end{array}$ \\
\hline
\end{tabular}

In general the marginal WTPs are lower in the cheap talk version, although, for some attributes, the WTP is higher in the cheap talk version. To formally test whether there are differences in marginal WTP, we apply the Complete Combinatorial test suggested by Poe et al. (2004). This is a non-parametric test that involves comparing differences in marginal WTP for all possible combinations of the estimates obtained by the Krinsky-Robb (1986) method; i.e. in our cases this implies 1,000,000 differences. For all chicken attributes, the marginal WTP is significantly higher in the experiment without cheap talk, at the $2 \%$ level, while, for the beef attributes, this only holds true for the two GMO attributes; the other beef attributes are not significantly different from each other. 


\section{Conclusions}

While the previous few tests of hypothetical bias in choice experiments are confined to the use of class room experiments or a closely controlled field setting, we conduct our test where CE is primarily used, that is, mail surveys. Drawing upon the results of previous tests of the influence of cheap talk and hypothetical bias, we use a cheap talk script as a test for hypothetical bias. Out of ten attributes, seven are found to be significantly less valued when the cheap talk script is used. This leads us to conclude: a) CE may also suffer from the alleged problem with CV surveys, namely, hypothetical bias; and b) a cheap talk script can significantly decrease the degree of inflated values. 


\section{References}

Bunch, D., Louviere, J. and Andersson D. (1996). A Comparison of Experimental Design Strategies for Choice-based Conjoint Analysis with Generic-attribute Multinomial Logit Models, Working Paper, Graduate School of Management, University of California, Davis.

Cameron, T., G. Poe, R. Ethier, and W. Schulze (2002) Alternative nonmarket valueelicitation methods: Are revealed and stated preferences the same? Journal of Environmental Economics and Management 44: 391-421.

Carlsson, F. and Martinsson, P. (2001). Do Hypothetical and Actual Marginal Willingness to Pay Differ in Choice Experiments? Journal of Environmental Economics and Management 27: 179-92.

Cummings, R.G. and Taylor, L.O. (1999). Unbiased Value Estimates for Environmental Goods: A Cheap Talk Design for the Contingent Valuation Method. American Economic Review 89: 649-65.

Johansson-Stenman, O. and H. Svedsäter (2003). Self Image and Choice Experiments: Hypothetical and Actual Willingness to Pay. Working Papers in Economics No. 94, Department of Economics, Gothenburg University.

Hanemann, M. (1984). Welfare evaluations in contingent valuation experiments with discrete responses. American Journal of Agricultural Economics 66: 332-41.

List, J.A. (2001). Do Explicit Warnings Eliminate the Hypothetical Bias in Elicitation Procedures? Evidence from Field Auctions for Sports Cards. American Economic Review 91: 1498-1507.

Krinsky, I. and A. Robb (1986). On Approximating the Statistical Properties of Elasticities. Review of Economics and Statistics 68: 715-719. 
Lusk, J.L. and Schroeder T.C. (2003). Are Choice Experiments Incentive Compatible? A Test with Quality Differentiated Beefsteaks. American Journal of Agricultural Economics 85: 840-856.

Poe, G., K. Giraud and J. Loomis (2004). Simple Computational Methods for Measuring the Difference of Empirical Distributions: Application to Internal and External Scope Tests in Contingent Valuation. American Journal of Agricultural Economics, forthcoming.

Swait, J. and J. Louviere. (1993) The Role of the Scale Parameter in the Estimation and Comparison of Multinomial Logit Models. Journal of Marketing Research 30, 305 314.

Train, K. (2003) Discrete Choice Methods with Simulation. Cambridge University Press, New York. 


\section{Choice 1, ground beef}

\begin{tabular}{|c|l|l|}
\hline $\begin{array}{c}\text { Attributes } \\
\text { ground beef }\end{array}$ & \multicolumn{1}{c|}{ Ground beef 1 } & \multicolumn{1}{c|}{ Ground beef 2 } \\
\hline \multicolumn{1}{|c|}{ Fodder } & Minimum required by law & $\begin{array}{l}\text { Farm of origin and choice of } \\
\text { animal husbandry } \\
\text { Genetically modified } \\
\text { products in fodder are } \\
\text { forbidden } \\
\text { Outdoor summertime } \\
\text { modified fodder has been used }\end{array}$ \\
Outdoor production \\
Transport to slaughter \\
$\begin{array}{l}\text { Mobile slaughter house } \\
\text { Price increase } \\
\text { SEK/kg }\end{array}$ & Outdoor all-year around \\
(total cost) & Transport of live animals \\
\hline $\begin{array}{c}\text { Your choice } \\
\text { (mark one alternative) }\end{array}$ & (SEK 44) & SEK 8 \\
\hline
\end{tabular}

